\title{
Small for gestational age and obesity: epidemiology and general risks
}

Hyo-Kyoung Nam, MD, PhD', Kee-Hyoung Lee, MD, $\mathrm{PhD}^{2}$

${ }^{1}$ Department of Pediatrics, Korea University Guro Hospital, College of Medicine, Korea University, Seoul, ${ }^{2}$ Department of Pediatrics, Korea University Anam Hospital, Korea University College of Medicine, Seoul, Korea

Received: 1 December, 2017

Accepted: 6 December, 2017

Address for correspondence: Kee-Hyoung Lee, MD, PhD

Department of Pediatrics, Korea University Anam Hospital, Korea University College of Medicine, 73 Inchon-ro, Seongbuk-gu, Seoul 02841, Korea

Tel: +82-2-920-5090

Fax: +82-2-922-7476

E-mail: khlee218@kumc.or.kr

https://orcid.org/0000-0002-43199019
Children born small for gestational age (SGA) have several life-long consequences. Previous epidemiological studies investigated from childhood to adulthood reported that a number of chronic diseases originate in the prenatal period. With the emerging era of obesity epidemic, more concerns are related to being obese than being short-statured in SGA children. The exact mechanisms are uncertain; however, growth hormone-insulin-like growth factor axis disturbance by fetal programming and accelerated postnatal weight gain contributed to central adiposity in SGA children. In this review, we summarized the definitions and prevalence of SGA, epidemiology, and general risks of obesity in SGA children. Early interventions, before and after birth, are needed for healthy catch-up growth to prevent later obesity and related complications.

Keywords: Small for gestational age, Obesity, Epidemiology

\section{Introduction}

Childhood obesity is an important public health concern because it is related to shortterm and long-term complications. It is related to various cardio-metabolic risk factors such as hyperglycemia, dyslipidemia, and hypertension. These comorbidities often persist in adulthood and result in increased morbidity and mortality. Children born small for gestational age (SGA) are a well-known group at a risk of obesity. The definition of SGA varies; it is most commonly defined as birth weight less than the $3 \mathrm{rd}$ percentile, 10th percentile, or -2 standard deviations compared with the mean birth length or body weight. ${ }^{1)}$ The etiology of SGA births is unclear; however, fetal factors (chromosomal abnormalities), maternal factors (socioeconomic status, maternal nutrition, smoking, alcohol consumption, pre-eclampsia, etc.), and environmental factors (placental infarction, infections) seem to affect low birthweight. ${ }^{2-4)}$ According to thrifty phenotype hypothesis, an SGA fetus adapts to an adverse intrauterine environment to survive, and switches to permanent glucose-insulin metabolism. ${ }^{5}$ However, reduced pancreatic capacity for insulin secretion and increased insulin resistance contribute to the development of metabolic disease in late adolescence and adulthood. In addition to effects of an adverse intrauterine environment, postnatal growth is also strongly associated with altered body composition. This review summarizes the epidemiology and general risks associated with obesity in SGA children that are important to prevent obesity and its related complications.

\section{Definitions and health implications of SGA}

Before 1960s, birth weight less than 2,500 g was classified as low birth weight. ${ }^{6}$ ) As there were differences in morbidity and mortality depending on the birth weight for gestational age, International Societies of Pediatric Endocrinology and the Growth Hormone Research Society (2007) suggested the criteria according to the birth weight for gestational age. SGA 
was defined with as follows: (1) knowing birth weight, length and head circumference with gestational age; (2) below the 10th percentile, ${ }^{7)}$ or below the 3 rd percentile, or less than -2 standard deviations from the mean weight for gestational age based on various criteria; (3) using international or population-specific references. ${ }^{1)}$

The prevalence of SGA births is approximately 8.6\%-9.6\% based on data from several countries. ${ }^{8-10)}$ The prevalence of SGA in South Korea was $11.4 \%$ using a cutoff of 10 th percentile based on the 5th Korean National Health and Nutrition Examination Survey. ${ }^{11)}$ Many studies have reported a higher prevalence of impaired glucose tolerance and metabolic syndrome in adults who were born SGA. Although the Fenton international and population-specific birth weight references identified a slightly different prevalence of SGA born $<29$ weeks and term SGA, higher risks of the composite outcomes compared with those appropriate for gestational age (AGA), were similar in them. ${ }^{12)}$

\section{Focus transition from a reduced risk to an increased risk of obesity}

Most of term SGA infants usually catch-up in growth until the age of 2 years and $85 \%-90 \%$ of all SGA infants would complete catching-up by the age of 4 years. ${ }^{13)}$ SGA children who do not undergo catch-up growth remain short statured adults. Children born term SGA had significant deficits in height of $6 \mathrm{~cm}$, weight of $8 \mathrm{~kg}$, and head circumference of $1.6 \mathrm{~cm}$ after adjustments for other factors. ${ }^{14)}$ Catch-up growth has advantages in terms of immune responses and neuro-development as well as body growth. Thus, until the late 1980s-1990s, a majority of studies focused on the long-term reductions in height, weight, body mass index (BMI), head circumference, and skinfold thicknesses. $^{13)}$

With the evolution of obesity epidemic, previous cohort studies have shown that growth compensation in early childhood leads to excess body weight in adulthood. ${ }^{15)}$ A metaanalysis of fourteen studies including 132,180 subjects found a U-shaped pattern on comparing type 2 diabetes according to birth weight. Both birth weight below 2,500 g and over 4,000 $\mathrm{g}$ were associated with high risk of diabetes compared with normal birth weight. ${ }^{16)}$

Many studies have evaluated the increased risk of obesity and metabolic syndrome later in life of infants born SGA; however, neither the proportion of SGA in childhood obesity nor the prevalence of obesity in SGA is known. In a Belarusian birth cohort study, $8.9 \%$ of subjects were born SGA and constituted only a small part of those who were overweight and obese compared with those who were born large for gestational age. ${ }^{17)}$

\section{A decrease in insulin sensitivity as a prenatal remodeling}

Of the etiologic factors responsible for SGA, approximately one-third are genetic variables and two-thirds are environmental factors such as maternal nutrition, ${ }^{4)}$ smoking, ${ }^{18)}$ alcohol, ${ }^{19)}$ and placental abruption. ${ }^{3)}$ Barker and Hales ${ }^{5)}$ proposed 'thrifty phenotype hypothesis,' which states that intrauterine malnutrition is a risk factor for the later development of adiposity and insulin resistance. In a large cohort study during the Dutch famine (1944-1945), increased obesity rates in adulthood were related to famine exposure during the first half of gestation rather than the last trimester of gestation. ${ }^{20)}$ Relationship between fetal exposure to famine and increased waist circumference were also observed during the Nigerian civil war $(1967-1970)^{21)}$

Exposure to 50\% caloric restriction during pregnancy resulted in $16 \%$ reduction in birth weight in Wistar rats. ${ }^{22)}$ Decreased beta-cell mass and insulin content suggested impaired beta-cell development following prenatal malnutrition.

Insulin-like growth factor-I (IGF-I) is important for fetal growth. ${ }^{23)}$ IGF-I gene polymorphisms and lower IGF-I standard deviation scores have recently been reported in subjects born SGA. ${ }^{24)}$ These polymorphisms include glucokinase and insulin as the contributing factors for fetal growth restriction. ${ }^{25)}$ IGF-I receptor proteins were more abundant in term and preterm SGA placentas compared with term AGA placenta. ${ }^{26)}$ AKT and mammalian target of rapamycin protein induced by IGF-I were also up-regulated in SGA placentas. Reduction in IGF-2 expression was also reported in SGA placenta. ${ }^{27)}$ These could be adaptive responses. Thus, abnormal placenta and fetal growth restriction modified gene expression and induced compensatory changes in IGF-I pathway result in insulin resistance.

\section{Effect of catch-up height and weight on obesity later}

Growth is accelerated soon after delivery from the intrauterine environment, especially in SGA babies. ${ }^{28)}$ It is not clear whether SGA children with catch-up growth in height are more obese later on. Cianfarani et al. ${ }^{29)}$ reported no association between postnatal growth and insulin sensitivity. In a Finnish study, children who were born with low weight, short body length, and thin body mass, followed by high growth rates between $0-7$ years of age, were found to have higher risk of type 2 diabetes and hypertension. ${ }^{30)}$ The hyperinsulinemic euglycemic clamp study also showed reduced insulin sensitivity, particularly in SGA children with catch-up height and higher BMI. ${ }^{31)}$ Insulin secretion was associated with catch-up height, whereas insulin sensitivity was more related to catch-up weight at 1 year of age. ${ }^{32)}$

Mechanisms implicated in catch-up weight and central adiposity are uncertain. One of them is the compensatory change in ghrelin and leptin levels, which are involved in the hyperphagic drive. Behavioral changes such as hyperphasia were observed in offsprings of Wistar rats with undernutrition. ${ }^{33)}$ Hyperleptinaemia was observed during catch-up growth in SGA infants. ${ }^{34)}$ Additionally, ghrelin level was increased after intravenous glucose infusion in SGA children and was found to be related with excess weight gain. ${ }^{35)}$ Reduction in the 
mass of skeletal muscles, which are essential sites of glucose disposal may contribute to the fat deposition during the catchup growth. A total of 4,431 infants and young children aged 2-47 months were assessed for an association between birth weight and body composition in an American national study (1988-1994), which found that there was a persistent deficit in lean body mass and less reduction in fat mass in children who were born SGA compared with children born large-forgestational age. ${ }^{8)}$ This resulted in higher percent body fat in SGA children. Large for gestational age children had a bigger body size with proportionate fat distribution, while SGA children were prone for excess fat deposition over the abdomen. ${ }^{36)}$ This central adiposity in SGA children resulted in higher insulin resistance and lower adiponectin levels in adolescence. ${ }^{37)}$ Another mechanism is that of suppressed thermogenesis. Lower energy expenditure during refeeding was observed in a starved rat compared with a weight-matched rat. By interfering with phosphatidylinositol 3-kinase and adenosine mono-phosphate activated protein kinase signaling, large discrepancies between energy intake and expenditure resulted predominantly in body fat increment. ${ }^{38,39)}$

\section{Rapid catch-up fat as postnatal risk factor}

Childhood obesity with accelerated weight gain is a wellknown risk factor for obesity in adulthood (Table 1). Increased weight gain during infancy was found to have a much stronger effect on body composition than birth weight. ${ }^{40)}$ RollandCachera et al. ${ }^{41)}$ introduced the term "early adiposity rebound" to describe the risks of rapid catch-up growth. Adiposity rebound is reported to usually occur at an age between 5-7 years in the Western countries.

Animal experiments in mice with restricted food supply during gestation or after birth demonstrated obesity by 6 months in mice that were born small and developed catch-up growth earlier. Mice born with normal weight and no catch-up growth were thinner and had better glucose tolerance. Timing of postnatal catch-up growth was also found to be important because the post-weaning period had a weak impact on weight gain compared to the weaning period. ${ }^{42)}$ Infancy is usually regarded as a more crucial period than other periods of growth.

Table 1. Summary of general risk factors for childhood obesity

\begin{tabular}{lc}
\hline General risk factors & Relative risk \\
\hline Birth weight (per $100 \mathrm{~g}$ ) & 1.1 \\
Maternal smoking (over 20 cigarettes) & 1.8 \\
Parental obesity (body mass index $>30 \mathrm{~kg} / \mathrm{cm}^{2}$ ) & 10.4 \\
Catch-up growth & 2.2 \\
Catch-down growth & 0.2 \\
Early childhood weight (at $8 \mathrm{mo})$ & 3.1 \\
Adiposity rebound & \\
Late (>61 mo) & 1.0 \\
Very early $(<43 \mathrm{mo})$ & 15.0 \\
\hline Da adapted from the study by Reilyet al
\end{tabular}

Data adapted from the study by Reilly et al. ${ }^{40)}$
In a Swedish cohort study, children who had large waist circumferences at the age of 17 years, were found to be 3 times more likely to gain weight during their shorter infancy period compared with early childhood. ${ }^{43)}$ In a Spanish cohort study, SGA children were found to be more likely to develop central adiposity between 2-4 years of age, and this transitional period was associated with weight gain before the age of 2 years. ${ }^{44)}$ When SGA infants experience rapid "catch-up growth," fat accumulation is increased immediately after birth and fat is predisposed to accumulate, particularly in the intra-abdominal area. Hence, the risk of obesity was greater in infancy. Changes from low insulin and IGF-I levels at birth to rapidly increased IGF-I levels over the first 3 years in SGA children were related with higher BMI, suggesting development of IGF-I resistance in the early catch-up growth. ${ }^{45}$

\section{Conclusions}

Increased long-term risks of adiposity, especially truncal adiposity, were demonstrated in children born SGA. Both genetic and environmental factors affect fetal growth. A decrease in insulin sensitivity and disturbances in the growth hormone-insulin-like growth factor axis are considered important results of a detrimental fetal environment. Despite the uncertain mechanisms, postnatal catch-up growth and rapid weight gain were the strongest additional factors influencing the insulin levels. By understanding the epidemiology and general risks of obesity in SGA, the future risk of insulin resistance can be prevented by trying to achieve a balance between the adverse pre- and postnatal environmental factors.

\section{Conflict of interest}

No potential conflict of interest relevant to this article was reported.

\section{References}

1. Clayton PE, Cianfarani S, Czernichow P, Johannsson G, Rapaport R, Rogol A. Management of the child born small for gestational age through to adulthood: a consensus statement of the International Societies of Pediatric Endocrinology and the Growth Hormone Research Society. J Clin Endocrinol Metab 2007;92:804-10.

2. McCowan L, Horgan RP. Risk factors for small for gestational age infants. Best Pract Res Clin Obstet Gynaecol 2009;23:779-93.

3. Ananth CV, Berkowitz GS, Savitz DA, Lapinski RH. Placental abruption and adverse perinatal outcomes. JAMA 1999;282:1646-51.

4. Fowles ER. Prenatal nutrition and birth outcomes. J Obstet Gynecol Neonatal Nurs 2004;33:809-22.

5. Hales CN, Barker DJ. Type 2 (non-insulin-dependent) diabetes mellitus: the thrifty phenotype hypothesis 
Diabetologia 1992;35:595-601.

6. Greer CF. Intrauterine growth as estimated from liveborn birth-weight data at 24 to 42 weeks of gestation, by Lula O. Lubchenco et al, Pediatrics, 1963;32:793-800. Pediatrics 1998;102(1 Pt 2):237-9.

7. World Health Organisation. ICD-10 version 2016. Certain conditions originating in the perinatal period. Ch. XV1. P05-08 [Internet]. Geneva (Switzerland): World Health Organisation; [cited 2017 Nov 20]. Available from: http:// apps.who.int/classifications/icd10/browse/2016/en\#!/ P05.9.

8. Hediger ML, Overpeck MD, Kuczmarski RJ, McGlynn A, Maurer KR, Davis WW. Muscularity and fatness of infants and young children born small- or large-for-gestationalage. Pediatrics 1998;102:E60.

9. Chen Y, Wu L, Zou L, Li G, Zhang W. Update on the birth weight standard and its diagnostic value in small for gestational age (SGA) infants in China. J Matern Fetal Neonatal Med 2017;30:801-7.

10. Lim JS, Lim SW, Ahn JH, Song BS, Shim KS, Hwang IT. New Korean reference for birth weight by gestational age and sex: data from the Korean Statistical Information Service (2008-2012). Ann Pediatr Endocrinol Metab 2014;19:14653.

11. Cho WK, Jung IA, Suh BK. Current growth status and metabolic parameters of Korean adolescents born small for gestational age: results from the Korea National Health and Nutrition Examination Surveys (KNHANES) 2010-2011. Pediatr Int 2014;56:344-8.

12. Martin LJ, Sjörs G, Reichman B, Darlow BA, Morisaki N, Modi N, et al. Country-specific vs. common birthweightfor-gestational age references to identify small for gestational age infants born at 24-28 weeks: an international study. Paediatr Perinat Epidemiol 2016;30:450-61.

13. Karlberg J, Albertsson-Wikland K. Growth in full-term small-for-gestational-age infants: from birth to final height. Pediatr Res 1995;38:733-9.

14. Westwood M, Kramer MS, Munz D, Lovett JM, Watters GV. Growth and development of full-term nonasphyxiated small-for-gestational-age newborns: follow-up through adolescence. Pediatrics 1983;71:376-82.

15. Binkin NJ, Yip R, Fleshood L, Trowbridge FL. Birth weight and childhood growth. Pediatrics 1988;82:828-34.

16. Harder T, Rodekamp E, Schellong K, Dudenhausen JW, Plagemann A. Birth weight and subsequent risk of type 2 diabetes: a meta-analysis. Am J Epidemiol 2007;165:849-57.

17. Kramer MS, Martin RM, Bogdanovich N, Vilchuk K, Dahhou M, Oken E. Is restricted fetal growth associated with later adiposity? Observational analysis of a randomized trial. Am J Clin Nutr 2014;100:176-81.

18. Lieberman E, Gremy I, Lang JM, Cohen AP. Low birthweight at term and the timing of fetal exposure to maternal smoking. Am J Public Health 1994;84:1127-31.

19. Pietrantoni M, Knuppel RA. Alcohol use in pregnancy. Clin Perinatol. 1991;18:93-111.

20. Ravelli GP, Stein ZA, Susser MW. Obesity in young men after famine exposure in utero and early infancy. N Engl J Med 1976;295:349-53.

21. Hult M, Tornhammar P, Ueda P, Chima C, Bonamy AK, Ozumba B, et al. Hypertension, diabetes and overweight: looming legacies of the Biafran famine. PLoS One 2010;5:e13582.

22. Garofano A, Czernichow P, Bréant B. In utero undernutrition impairs rat beta-cell development. Diabetologia 1997;40:1231-4.

23. Roth CL, Sathyanarayana S. Mechanisms affecting neuroendocrine and epigenetic regulation of body weight and onset of puberty: potential implications in the child born small for gestational age (SGA). Rev Endocr Metab Disord 2012;13:129-40.

24. Johnston LB, Dahlgren J, Leger J, Gelander L, Savage MO, Czernichow $\mathrm{P}$, et al. Association between insulin-like growth factor I (IGF-I) polymorphisms, circulating IGF-I, and pre- and postnatal growth in two European small for gestational age populations. J Clin Endocrinol Metab 2003;88:4805-10.

25. Hattersley AT, Beards F, Ballantyne E, Appleton M, Harvey $\mathrm{R}$, Ellard S. Mutations in the glucokinase gene of the fetus result in reduced birth weight. Nat Genet 1998;19:268-70.

26. Iñiguez G, Castro JJ, Garcia M, Kakarieka E, Johnson MC, Cassorla F, et al. IGF-IR signal transduction protein content and its activation by IGF-I in human placentas: relationship with gestational age and birth weight. PLoS One 2014;9:e102252.

27. Bourque DK, Avila L, Peñaherrera M, von Dadelszen P, Robinson WP. Decreased placental methylation at the H19/IGF2 imprinting control region is associated with normotensive intrauterine growth restriction but not preeclampsia. Placenta 2010;31:197-202.

28. Hokken-Koelega AC, De Ridder MA, Lemmen RJ, Den Hartog H, De Muinck Keizer-Schrama SM, Drop SL. Children born small for gestational age: do they catch up? Pediatr Res 1995;38:267-71.

29. Cianfarani S, Geremia C, Germani D, Scirè G, Maiorana A, Boemi S. Insulin resistance and insulin-like growth factors in children with intrauterine growth retardation. Is catchup growth a risk factor? Horm Res 2001;55 Suppl 1:7-10.

30. Forsén T, Eriksson J, Tuomilehto J, Reunanen A, Osmond C, Barker D. The fetal and childhood growth of persons who develop type 2 diabetes. Ann Intern Med. 2000;133:176-82.

31. Veening MA, Van Weissenbruch MM, Delemarre-Van De Waal HA. Glucose tolerance, insulin sensitivity, and insulin secretion in children born small for gestational age. J Clin Endocrinol Metab 2002;87:4657-61.

32. Soto N, Bazaes RA, Peña V, Salazar T, Avila A, Iñiguez G, et al. Insulin sensitivity and secretion are related to catch-up growth in small-for-gestational-age infants at age 1 year: results from a prospective cohort. J Clin Endocrinol Metab 2003;88:3645-50.

33. Vickers MH, Breier BH, McCarthy D, Gluckman PD. Sedentary behavior during postnatal life is determined by the prenatal environment and exacerbated by postnatal 
hypercaloric nutrition. Am J Physiol Regul Integr Comp Physiol 2003;285:R271-3.

34. Jaquet D, Leger J, Tabone MD, Czernichow P, LevyMarchal C. High serum leptin concentrations during catch-up growth of children born with intrauterine growth retardation. J Clin Endocrinol Metab 1999;84:1949-53.

35. Iñiguez G, Ong K, Peña V, Avila A, Dunger D, Mericq V. Fasting and post-glucose ghrelin levels in SGA infants: relationships with size and weight gain at one year of age. J Clin Endocrinol Metab 2002;87:5830-3.

36. Biosca M, Rodríguez G, Ventura P, Samper MP, Labayen I, Collado MP, et al. Central adiposity in children born small and large for gestational age. Nutr Hosp 2011;26:971-6.

37. Crume TL, Scherzinger A, Stamm E, McDuffie R, Bischoff $\mathrm{KJ}$, Hamman RF, et al. The long-term impact of intrauterine growth restriction in a diverse U.S. cohort of children: the EPOCH study. Obesity (Silver Spring) 2014;22:608-15.

38. Dulloo AG, Jacquet J. An adipose-specific control of thermogenesis in body weight regulation. Int J Obes Relat Metab Disord 2001;25 Suppl 5:S22-9.

39. Crescenzo R, Samec S, Antic V, Rohner-Jeanrenaud F, Seydoux J, Montani JP, er al. A role for suppressed thermogenesis favoring catch-up fat in the pathophysiology of catch-up growth. Diabetes 2003;52:1090-7.
40. Reilly JJ, Armstrong J, Dorosty AR, Emmett PM, Ness A, Rogers I, et al. Early life risk factors for obesity in childhood: cohort study. BMJ 2005;330:1357.

41. Rolland-Cachera MF, Deheeger M, Bellisle F, Sempé $\mathrm{M}$, Guilloud-Bataille M, Patois E. Adiposity rebound in children: a simple indicator for predicting obesity. Am J Clin Nutr 1984;39:129-35.

42. Jimenez-Chillaron JC, Hernandez-Valencia M, Lightner A, Faucette RR, Reamer C, Przybyla R, et al. Reductions in caloric intake and early postnatal growth prevent glucose intolerance and obesity associated with low birthweight. Diabetologia 2006;49:1974-84.

43. Ekelund U, Ong K, Linné Y, Neovius M, Brage S, Dunger DB, et al. Upward weight percentile crossing in infancy and early childhood independently predicts fat mass in young adults: the Stockholm Weight Development Study (SWEDES). Am J Clin Nutr 2006;83:324-30.

44. Ibáñez L, Ong K, Dunger DB, de Zegher F. Early development of adiposity and insulin resistance after catchup weight gain in small-for-gestational-age children. J Clin Endocrinol Metab 2006;91:2153-8.

45. Mericq V, Ong KK, Bazaes R, Peña V, Avila A, Salazar T, et al. Longitudinal changes in insulin sensitivity and secretion from birth to age three years in small- and appropriate-forgestational-age children. Diabetologia 2005;48:2609-14. 